\title{
Cataract Extraction and Toric Intraocular Lens Implantation for the Management of Pellucid Marginal Degeneration and Cataract
}

\author{
Irit Bahar, Omer Bialer
}

\begin{abstract}
We report cataract surgery with toric intraocular lens implantation for the management of senile cataract combined with pellucid marginal degeneration. A 72-year-old man with bilateral senile cataract and significant against-the-rule astigmatism sought counseling for blurry vision and glare, mostly in the right eye. Based on ophthalmic examination and corneal topography, a diagnosis of pellucid marginal degeneration and cataract was made. Since visual acuity and refraction had been stable in the past 3 years, the patient underwent cataract extraction and implantation of a custom-designed toric posterior chamber intraocular lens. Postoperative follow-up of 1.5-year demonstrated marked improvement in visual acuity, stable refraction and patient satisfaction. This treatment for pellucid marginal degeneration offers the simplicity of regular cataract surgery, and avoids the known complications of keratoplasty and other corneal surgical manipulation for the management of pellucid marginal degeneration.
\end{abstract}

Keywords: Pellucid marginal degeneration, Cataract, Astigmatism, Toric IOL.

How to cite this article: Bahar I, Bialer O. Cataract Extraction and Toric Intraocular Lens Implantation for the Management of Pellucid Marginal Degeneration and Cataract. Int J Keratoco Ectatic Corneal Dis 2012;1(1):66-67.

\section{Source of support: Nil}

Conflict of interest: None declared

\section{INTRODUCTION}

Pellucid marginal corneal degeneration (PMD) is a progressive, idiopathic, noninflammatory peripheral ectatic corneal disorder. ${ }^{1}$ Most patients with PMD are managed successfully with refractive correction. ${ }^{2}$ The gold standard for surgical management is penetrating keratoplasty, ${ }^{3}$ yet the large diameter and eccentric corneal graft, necessary for the correction of the peripheral corneal ectasia, results in a greater incidence of graft-related complications and unpredictable refractive outcome. ${ }^{4}$ Therefore, other surgical modalities of treatment have been previously published. ${ }^{4-5}$

\section{CASE REPORT}

A 72-year-old man was referred to our cornea service due to senile cataract and marked corneal astigmatism OU. His main complaint was blurred vision and glare that could not be corrected with spectacles and was attributed to the presence of cataract. The patient's refraction had been stable during the past 3 years.
Best corrected visual acuity was 20/50 OD and 20/25 OS. Spectacle refraction was +3.5-6.0× 87 OD, and +3.0$4.25 \times 90$ OS. Intraocular pressure (IOP) was normal OU. Both corneas demonstrated bilateral inferior crescentic peripheral thinning and steepening, separated from the inferior limbus by normal cornea, without scars or iron lines (Fig. 1A). There was bilateral nuclear sclerosis and posterior subcapsular cataract, more marked in the right eye. Funduscopy was normal.

Corneal topography was preformed using the Oculus Pentacam $^{\mathrm{TM}}$ (Oculus Ltd, Optikgerate, Wetzlar, Germany) and demonstrated against-the-rule astigmatism, with the 'lobster claw' sign (Fig. 1B). Keratometry readings were 48.4D/37.7D OD and 44.1D/41.3D OS. Corneal astigmatism was 10.7D OD and 2.8D OS. The patient was referred for cataract extraction surgery with implantation of a toric IOL.

An uneventful cataract surgery was performed within the bag implantation of a custom-made Rayner T-flex ${ }^{\mathrm{TM}}$ (Rayner Ltd, East Sussex, UK) toric IOL.

On postoperative day 1, the patient's uncorrected visual acuity was 20/30. On the last follow-up exam, 1.5 year postsurgery, a well-positioned PCIOL in the capsular bag (Fig. 1C) was noticed. Refraction was $+1.0-2.5 \times 90^{\circ} \mathrm{OD}$ (SE-0.25D), UCVA was 20/30 and BCVA was 20/20. The rest of the ocular examination remained unchanged.

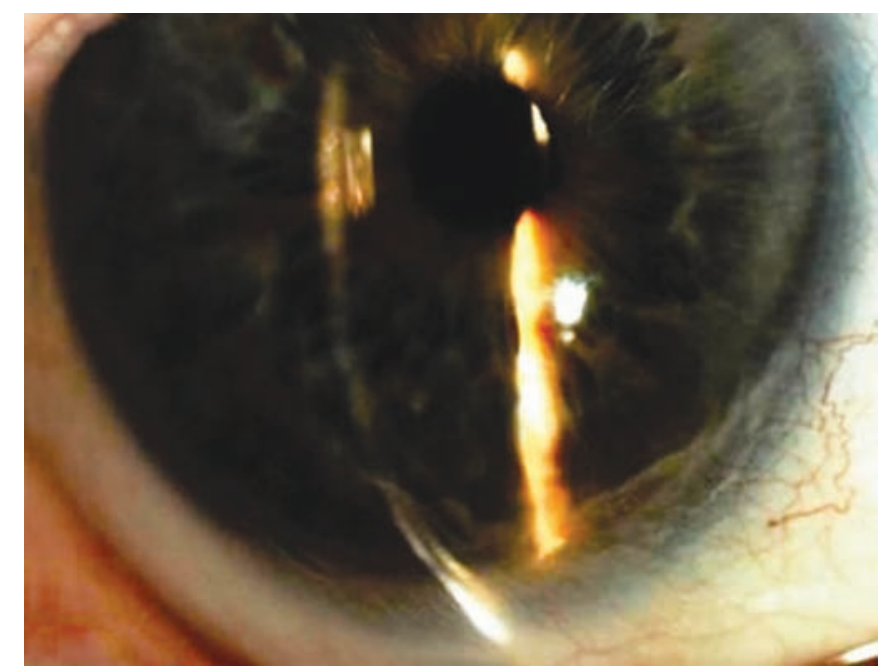

Fig. 1A: Slit lamp photography of the right eye (magnification $\times 16$ ) showing a clear cornea with a prominent band of inferior thinning 


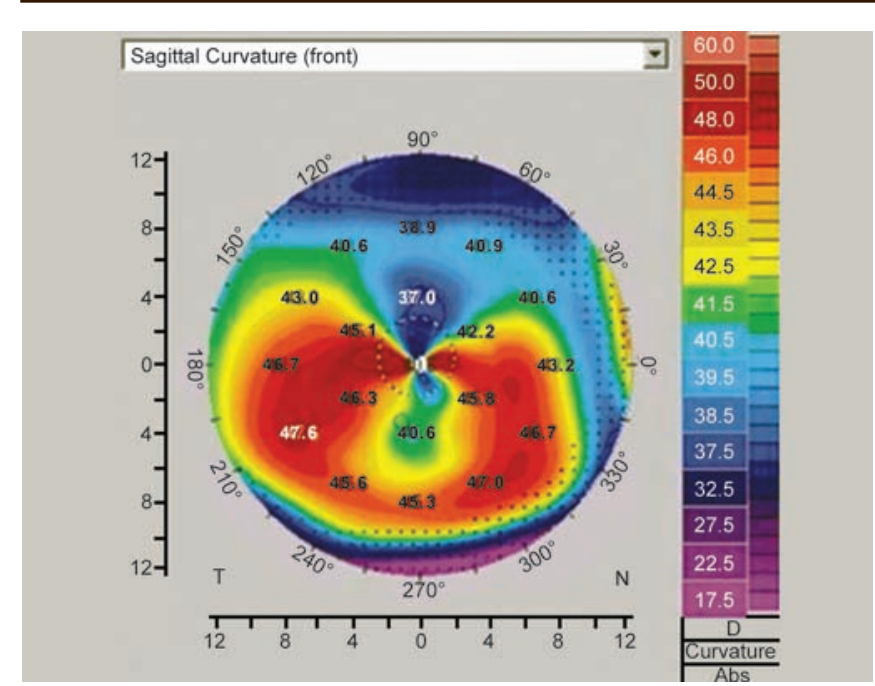

Fig. 1B: Pentacam's sagittal curvature map demonstrating high against-the-rule astigmatism with peripheral inferior corneal steepening and pellucid marginal degeneration's typical 'lobster claw' sign

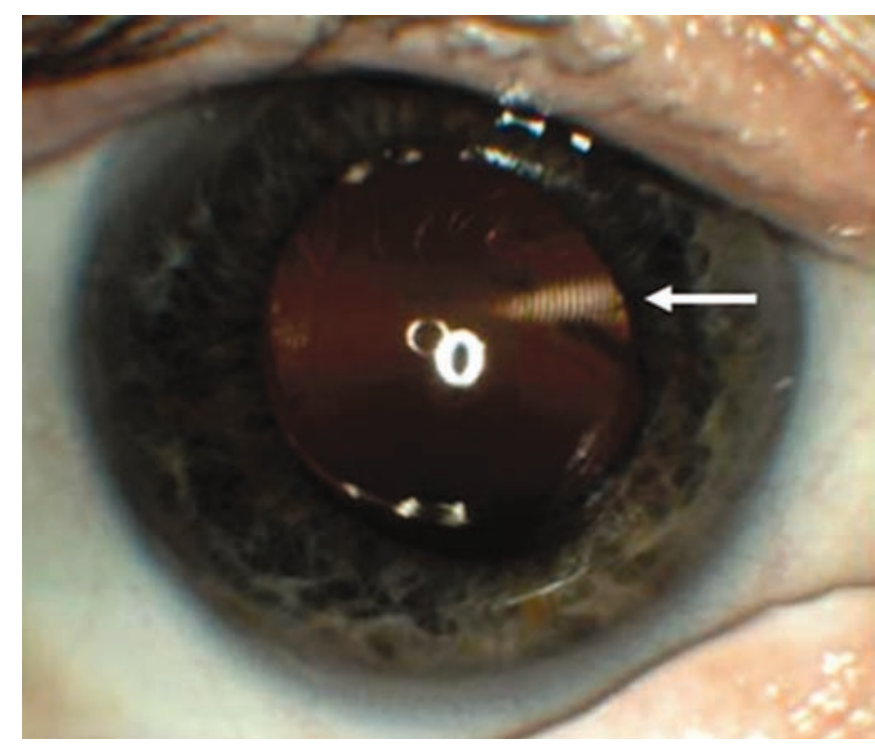

Fig. 1C: Slit lamp photography of the right eye, using retroillumination, to demonstrate the well-positioned toric intraocular lens in the capsular bag with the arrow marking imprint of the cylinder axis on the IOL

\section{DISCUSSION}

In this clinical case, we report an alternative and successful treatment for PMD. As previously reported, most PMD patients can be managed with spectacles or contact lenses. ${ }^{2}$ Penetrating keratoplasty is still considered the classic surgical management for $\mathrm{PMD},{ }^{3}$ yet several other options for treatment have been previously described in the literature, including compressive deep anterior lamellar, wedge resection, intracorneal ring segments and simultaneous photorefractive keratectomy and collagen cross-linking.
In a study by de Vries et al, ${ }^{4}$ phakic toric IOL implantation with the Artisan iris fixated lens in a patient with PMD and high myopia resulted in refraction close to emmetropia. Finally, Rodriguez-Gonzales-Herrero et $\mathrm{al}^{5}$ reported a patient with bilateral PMD and senile cataract, who underwent a combined cataract extraction with spherical IOL implantation and corneal wedge resection.

Luck J published, in 2010, a report on a toric PCIOL implantation in the capsular bag to correct high astigmatism of PMD and cataract, with excellent results during 3 months of follow-up. ${ }^{6}$ Our results also support the fact that this procedure addresses both problems simultaneously, whilst avoiding a possibly difficult manipulation of the cornea and any future corneal graft-related complications. The longer follow-up, presented here, emphasizes the safety and stability of the outcomes, implying that the toric IOL may be a good treatment option in patients with stable PMD and cataract.

\section{CONCLUSION}

Although our report involves a single case, this procedure offers a different modality of surgical management for PMD and cataract with significant advantages over corneal manipulation. Longer follow-up is still needed.

\section{REFERENCES}

1. Krachmer JH. Pellucid marginal corneal degeneration. Arch Ophthalmol 1978;96:1217-21.

2. Tzelikis PF, Cohen EJ, Rapuano CJ, et al. Management of pellucid marginal corneal degeneration. Cornea 2005;24: 555-60.

3. Varley GA, Macsai MS, Krachmer JH. The results of penetrating keratoplasty for pellucid marginal corneal degeneration. Am J Ophthalmol 15 Aug 1990;110(2):149-52.

4. de Vries NE, Tahzib NG, Webers CA, et al. Use of verisyse/ Artisan phakic intraocular lens for the reduction of myopia in a patient with pellucid marginal degeneration. Cornea 2008;27(2):241-45.

5. Rodrguez-Gonzales-Herrero ME, Ortega AR, Mora-Figueroa JM. Surgical treatment of pellucid marginal degeneration associated with cataract. J Cataract Refract Surg 2000;26(3): 309-11.

6. Luck J. Customized ultra-high-power toric intraocular lens implantation for pellucid marginal degeneration and cataract. J Cataract Refract Surg Jul 2010;36(7):1235-38.

\section{ABOUT THE AUTHORS}

\section{Irit Bahar (Corresponding Author)}

Director, Department of Ophthalmology, Cornea Service, Rabin Medical Center, Israel, e-mail: iritbahar@yahoo.com

\section{Omer Bialer}

Resident, Department of Ophthalmology, Rabin Medical Center, Israel 